\title{
Prevalence of the Signs and Symptoms of Temporomandibular Joint Disorders among Dental Students in Navi Mumbai
}

\author{
Pooja Bhave ${ }^{1}$, Jyoti Nadgere ${ }^{2}$, Sabita Ram ${ }^{3}$, Janani lyer ${ }^{4}$
}

\begin{abstract}
Aim and objective: To determine the prevalence of the signs and symptoms of temporomandibular joint disorders (TMDs) among dental students in Navi Mumbai.

Materials and methods: A representative population-based sample of 500 dental students was evaluated for the signs and symptoms of TMD by means of a validated questionnaire. A detailed case history was taken, and the examination of the temporomandibular joint (TMJ), mandibular movements, muscles and occlusion was done for each participant.

Results: The signs and symptoms of TMD are frequent among dental students. Out of 500 students, who filled the questionnaire and underwent examination, 250 were females and 250 were males. In total, $22 \%$ of the study population had at least one symptom of TMD. In total, $51 \%$ of the study population had at least one sign of TMD. The prevalence of the signs and symptom of TMD was significantly higher in females than in males. Conclusion: The study showed that about $29 \%$ of the study population had at least one sign without any symptoms of TMD. This highlights the presence of subclinical cases that exist in the population that can be intervened to prevent their progression into TMD.

Clinical significance: Extra emphasis should be given on the determination of the predisposing, initiating and causative factors of TMD along with the examination. Prevention and treatment at an early stage will prevent the progression of TMD.
\end{abstract}

Keywords: Clicking, Occlusion, Pain, Prevalence, Signs and symptoms, Temporomandibular joint disorders.

Journal of Contemporary Dentistry (2019): 10.5005/jp-journals-10031-1265

\section{INTRODUCTION}

Temporomandibular joint disorders (TMDs) include a wide range of conditions. It is a collective term for a number of clinical signs and symptoms involving the masticatory muscles, the temporomandibular joint (TMJ), and associated structures. Temporomandibular joint disorders have been the subject of extensive interest because of its multifactorial etiology such as bruxism, occlusion, postural, metabolic, structural, traumatic, psychological, social and behavioral influences, which have been identified as possible predisposing, initiating, and maintaining factors for TMD. ${ }^{1}$

Certain nonpatient prevalence studies have reported that approximately $50-75 \%$ of participants exhibit one or more signs of TMD and $33 \%$ have at least one symptom. ${ }^{2}$

Temporomandibular joint disorder may be present in the subclinical form and the patient may not be able to relate to its cause. Studies also show that $15-20 \%$ of signs may lead to symptoms at a later date which may require extensive and complex treatment. ${ }^{3}$ It is thus important to identify the signs of the possible TMDs to diagnose the condition.

Accessing prevalence of the sign and symptoms of TMDs in a given population can provide us the possible etiologies and help us identify predisposing factors leading to TMD. In this study, dental students were selected as participants as bringing about adequate awareness among the dental students about their own condition will help them recognize the importance of TMDs in dental practice.

The purpose of this study was thus to observe the prevalence of signs and symptoms of TMD among dental students.

\section{Materials and Methods}

\section{Sample Selection}

Navi Mumbai is a major city with a number of educational institutions. It has five dental colleges with approximately 2,500
${ }^{1-4}$ Department of Prosthodontics, Crown and Bridge, MGM Dental College and Hospital, Navi Mumbai, Maharashtra, India

Corresponding Author: Pooja Bhave, Department of Prosthodontics, Crown and Bridge, MGM Dental College and Hospital, Navi Mumbai, Maharashtra, India, Phone: +91 8169820970, e-mail: poojavbhave92@ gmail.com

How to cite this article: Bhave P, Nadgere J, Ram S, et al. Prevalence of the Signs and Symptoms of Temporomandibular Joint Disorders among Dental Students in Navi Mumbai. J Contemp Dent 2019;9(3): 113-116.

Source of support: Nil

Conflict of interest: None

students. A descriptive cross-sectional survey was planned among the dental students of Navi Mumbai. Ethical approval was obtained from the Institutional Ethics Committee, MGM Dental College and Hospital. The participants were explained the nature of the study, and the students were required to sign an informed consent before their participation in the study. Students studying in dental colleges of Navi Mumbai and students in the age group of 18-25 years were included in the study. Students from other streams of education and students below 18 years of age and above 25 years of age were not included in the study.

\section{Self-reported Questionnaire}

The questionnaire for the survey was designed referring the research diagnostic criteria (RDC/TMD). The RDC/TMD 4 is based on a detailed psychological as well as physical examination for the signs and symptoms of TMD. The questionnaire was validated by four subject experts and two language experts from MGM Dental College. The questionnaire consisted of 25 questions, evaluating

(c) The Author(s). 2019 Open Access This article is distributed under the terms of the Creative Commons Attribution 4.0 International License (https:// creativecommons.org/licenses/by-nc/4.0/), which permits unrestricted use, distribution, and non-commercial reproduction in any medium, provided you give appropriate credit to the original author(s) and the source, provide a link to the Creative Commons license, and indicate if changes were made. The Creative Commons Public Domain Dedication waiver (http://creativecommons.org/publicdomain/zero/1.0/) applies to the data made available in this article, unless otherwise stated. 
for the presence of pain in TMJ and associated structures, pain while chewing, parafunctional habits, limitation of movements, joint clicking, perception of malocclusion and emotional stress and orthodontic therapy. The participants were thoroughly explained each and every question before filling out the questionnaire. The participants answered either "yes" or "no" to the given questions. Only participants that reported at least one symptom of TMD completed the entire questionnaire.

\section{Examination}

Selection of 10 dentists was done who were trained to take a detailed case history of the participants. They were also trained to carry out a thorough examination of the TMJ and associated structures. Each dentist was allotted 50 students for the recording of the history and the examination. A detailed case history was recorded for each participant. Clinical and physical assessment of the TMJ was done by manual palpation of the muscles and TMJ to evaluate the tenderness of intraoral and extraoral jaw muscles, neck muscles, and TMJ capsule. A thorough examination of the mandibular movements, masticatory muscles, and occlusion was done by the trained dentists. A month was required to complete the study.

\section{Analysis of Data}

Data were entered into Microsoft Excel and analyzed using Statistical Package for the Social Sciences (SPSS) version 21.0 (SPSS, Inc., Chicago, IL, USA). Chi-square test was applied to evaluate the association between the presence of signs and symptoms of TMD and gender. For all the tests, the level of significance was set up at $p<0.05$.

\section{Results}

Out of 500 students, who filled the questionnaire and underwent examination, 250 were females and 250 were males. Results of the participant reported symptoms with the relative percentages are depicted in Table 1. In total, $22 \%$ of the study population had at least one symptom of TMD with pain and clicking being the most common symptoms (Fig. 1).

Results of the examination for the signs of TMD by the trained dentist with the relative percentages are depicted in Table 2. In total, $51 \%$ of the study population had at least one sign of TMD. Clicking and jaw deviation were the most common signs seen among the study group (Fig. 2).

The prevalence of the signs and symptoms of TMD and their association with gender has been depicted in Tables 3 and 4. The prevalence of the signs and symptoms of TMD was significantly higher in females than in males.

\section{Discussion}

Temporomandibular joint disorders are a group of musculoskeletal and neuromuscular conditions involving the TMJ complex and associated components. Temporomandibular joint disorder affects up to $15 \%$ of adults, with a peak incidence at $20-40$ years of age. ${ }^{1}$ Investigations on TMD have revealed predominately mild signs and symptoms already present in childhood. An increase in symptoms occurs until young adulthood. Studies have revealed that around $60-75 \%$ of the subjects will manifest one TMD sign and $35 \%$ of subjects will have mild TMD symptoms. ${ }^{2}$
Table 1: Self-reported questionnaire

\begin{tabular}{|c|c|c|c|c|}
\hline \multirow{2}{*}{$\begin{array}{l}\text { Participant reported } \\
\text { symptoms of TMD }\end{array}$} & \multirow{2}{*}{$\begin{array}{l}\text { Female } \\
n(250) \\
\end{array}$} & \multirow{2}{*}{$\frac{\text { Males }}{n(250)}$} & \multirow{2}{*}{$\begin{array}{l}\text { Total } \\
(n=500)\end{array}$} & \multirow{2}{*}{ Percentage } \\
\hline & & & & \\
\hline $\begin{array}{l}\text { Pain in TMJ, temple nape } \\
\text { of neck, forehead, and } \\
\text { associated structures }\end{array}$ & 25 & 6 & 31 & 6.2 \\
\hline $\begin{array}{l}\text { Grating, clicking, popping } \\
\text { sounds }\end{array}$ & 26 & 13 & 39 & 7.8 \\
\hline $\begin{array}{l}\text { Locking or painful jaw in } \\
\text { the morning }\end{array}$ & 6 & 2 & 8 & 1.6 \\
\hline $\begin{array}{l}\text { Difficulty in jaw } \\
\text { movements }\end{array}$ & 6 & 2 & 8 & 1.6 \\
\hline Difficulty in chewing & 4 & 2 & 6 & 1.2 \\
\hline $\begin{array}{l}\text { Deviation of the jaw while } \\
\text { opening }\end{array}$ & 10 & 9 & 19 & 3.8 \\
\hline $\begin{array}{l}\text { Sensation of pressure, } \\
\text { blockage, ringing, hissing, } \\
\text { buzzing in the ear }\end{array}$ & 7 & 5 & 12 & 2.4 \\
\hline Clenching during the day & 9 & 7 & 16 & 3.2 \\
\hline Grinding in the night & 4 & 3 & 7 & 1.4 \\
\hline $\begin{array}{l}\text { Sensation of dizziness or } \\
\text { fainting }\end{array}$ & 6 & 2 & 8 & 1.6 \\
\hline $\begin{array}{l}\text { Chronic fatigue and } \\
\text { anxiety }\end{array}$ & 4 & 2 & 6 & 1.2 \\
\hline Parafunctional habits & 4 & 5 & 9 & 1.8 \\
\hline Finger numbness & 6 & 4 & 10 & 2.0 \\
\hline Back teeth missing & 4 & 3 & 7 & 1.4 \\
\hline $\begin{array}{l}\text { Extensive crown and } \\
\text { bridge work }\end{array}$ & 0 & 0 & 0 & 0 \\
\hline Frequent headaches & 10 & 8 & 18 & 3.6 \\
\hline $\begin{array}{l}\text { Cervical collar or neck } \\
\text { traction }\end{array}$ & 0 & 0 & 0 & 0 \\
\hline Blow to the chin, face, head & 1 & 1 & 2 & 0.4 \\
\hline Whiplash injury & 0 & 0 & 0 & 0 \\
\hline $\begin{array}{l}\text { Chewing gum starts TMD } \\
\text { pain }\end{array}$ & 4 & 3 & 7 & 1.4 \\
\hline $\begin{array}{l}\text { History of orthodontic } \\
\text { treatment }\end{array}$ & 9 & 6 & 15 & 3.0 \\
\hline Bite adjusted by the dentist & 6 & 3 & 9 & 1.8 \\
\hline $\begin{array}{l}\text { Any treatment received for } \\
\text { TMD pain }\end{array}$ & 1 & 1 & 2 & 0.4 \\
\hline
\end{tabular}

The assessment of subclinical TMD is crucial for identifying patients apt to develop clinical signs of TMD, because the adaptive and/ or compensatory mechanisms are more likely to fail in those with subclinical TMD than in healthy individuals. ${ }^{5}$ The present study was thus conducted to assess the prevalence of the signs and symptoms of TMD in dental students of Navi Mumbai, India, by the use of self-reported questionnaire followed by a thorough case history and examination of the TMJ and associated structures of the participants. The questionnaire and examination allowed collection of a good quantity of information in a relatively short period of time with less cost and with better understanding. In total, $6.2 \%$ of the study population reported of pain in the TMJ and associated structures. Other reported symptoms by the students were clicking and jaw deviation. Participant reported clicking was $7.8 \%$, while examination of the same population revealed $15.8 \%$ 


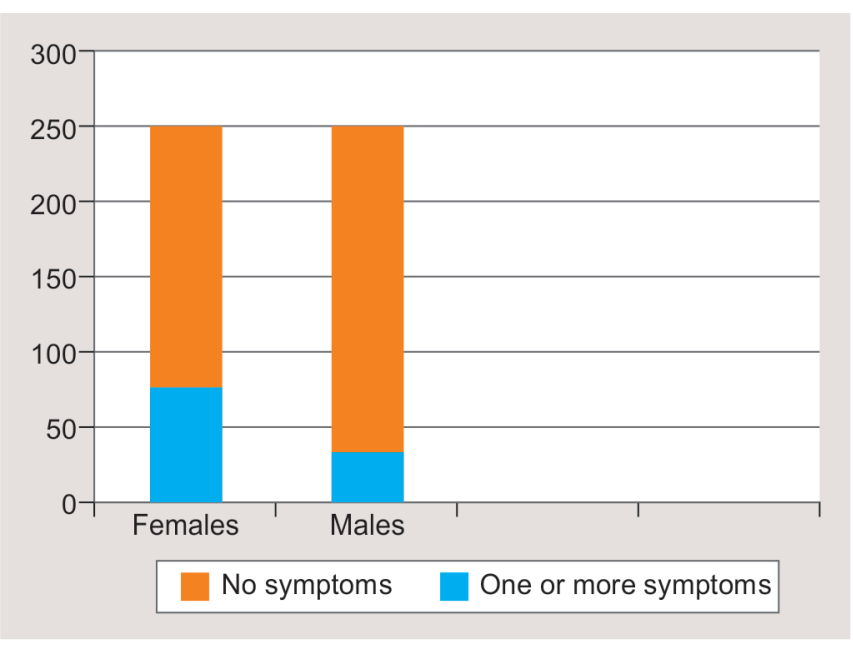

Fig. 1: Presence of one or more symptoms of temporomandibular joint disorders according to sex

Table 2: Examination of the participants by trained dentist

\begin{tabular}{|c|c|c|c|c|}
\hline \multirow{2}{*}{$\begin{array}{l}\text { Signs of TMD evaluated by } \\
\text { examination }\end{array}$} & \multirow{2}{*}{$\begin{array}{c}\begin{array}{c}\mathrm{Fe}- \\
\text { males }\end{array} \\
n(250)\end{array}$} & \multirow{2}{*}{$\frac{\text { Males }}{n(250)}$} & \multirow{2}{*}{$\begin{array}{l}\text { Total } \\
(n=500)\end{array}$} & \multirow[b]{2}{*}{ Percentage } \\
\hline & & & & \\
\hline Relevant medical history & 3 & 1 & 4 & 0.8 \\
\hline Gross facial asymmetry & 0 & 0 & 0 & 0.0 \\
\hline Limited mouth opening & 3 & 1 & 4 & 0.8 \\
\hline $\begin{array}{l}\text { Jaw deviation while } \\
\text { opening }\end{array}$ & 55 & 36 & 91 & 18.2 \\
\hline $\begin{array}{l}\text { Restricted excursive } \\
\text { movements }\end{array}$ & 8 & 4 & 12 & \\
\hline Clicking & 50 & 29 & 79 & 15.8 \\
\hline Crepitus & 0 & 0 & 0 & 0 \\
\hline $\begin{array}{l}\text { Muscle tenderness on } \\
\text { palpation }\end{array}$ & 40 & 26 & 66 & 13.2 \\
\hline $\begin{array}{l}\text { Angles class II and class III } \\
\text { occlusion }\end{array}$ & 18 & 22 & 30 & 6 \\
\hline $\begin{array}{l}\text { Mutually protected } \\
\text { occlusion }\end{array}$ & 180 & 220 & 400 & 80 \\
\hline Canine-guided occlusion & 180 & 220 & 400 & 80 \\
\hline $\begin{array}{l}\text { Group function type of } \\
\text { occlusion }\end{array}$ & 60 & 40 & 100 & 20 \\
\hline Protrusive interferences & 26 & 11 & 37 & 7.4 \\
\hline Excursive interferences & 47 & 23 & 70 & 14 \\
\hline
\end{tabular}

clicking in the study population. Temporomandibular joint click sound is commonly recognized as a sign of internal derangement and is usually associated with disk displacement with reduction. ${ }^{6}$ Jaw deviation was a common finding reported among $18.2 \%$ population in this study.

Among the total population that demonstrated at least one symptom of TMD, $17 \%$ reported day clenching, $7.5 \%$ reported night grinding, 5.8\% students had one or more back tooth missing, $5 \%$ reported frequent headaches, and $12 \%$ reported history of orthodontic treatment. These could be considered as predisposing or initiating factors for TMD. ${ }^{5,7-12}$ It is also possible that some of the subjective and objective findings existed because of orofacial

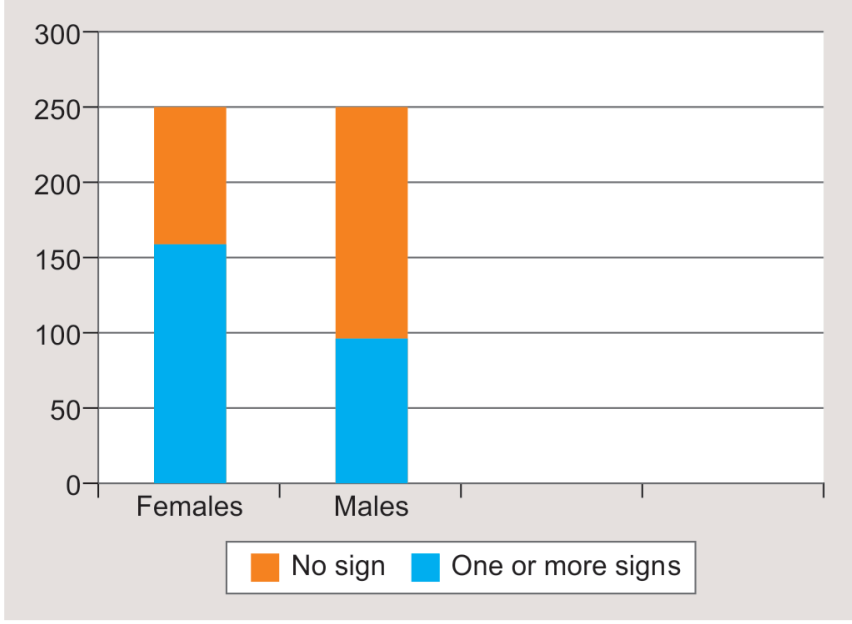

Fig. 2: Presence of one or more signs of temporomandibular joint disorders according to sex

Table 3: Presence of one or more symptoms of temporomandibular joint disorders according to sex

\begin{tabular}{lll}
\hline & One or more symptom & No symptom \\
\hline Females & 77 & 173 \\
Males & 34 & 216 \\
$p$ value & 0.000004 & \\
\hline
\end{tabular}

As the $p$ value is $<0.05$, there is more prevalence of the symptom of TMD among females than in males

Table 4: Presence of one or more signs of temporomandibular joint disorders according to sex

\begin{tabular}{llc}
\hline & One or more sign & No sign \\
\hline Females & 159 & 91 \\
Males & 97 & 153 \\
$p$ value & 0.000000 & \\
\hline
\end{tabular}

As the $p$ value is $<0.05$, there is more prevalence of the signs of TMD among females than in males

disorders other than TMD. This would result in an overestimation of the prevalence of TMD.

A detailed examination of the occlusion of the participants revealed $20 \%$ students did not have a mutually protected occlusion. In total, $11 \%$ students had a group function type of occlusion with interferences in lateral excursions. In total, $7.4 \%$ of the study population displayed protrusive interferences. Not all participants having a group function type of occlusion had subjective symptoms of TMD. This could possibly be because the TMJ and associated structures were adapted to the existing occlusion, but they are at an increased risk of developing TMD in the future. Out of the participants that reported at least one symptom of TMD, $40 \%$ represented a group function type of occlusion with protrusive and excursive interferences. Muscle tenderness was reported among $13 \%$ of the total population. Out of the various muscles, palpated tenderness was reported the most for the temporalis muscle.

Within the total study group, females had a greater prevalence of all subjective symptoms. Seventy-seven out of 250 females and 34 out 250 males reported with at least one symptom of TMD. 
Female students in this study were reported to have signs of TMDs more than men with as much as a $50 \%$. This is similar to the results done in the previous studies by Graue et al., Solberg et al., Klineberg et al., Shiau and Chang. ${ }^{13-15}$ An epidemiological study of an African population by Beighton et al. ${ }^{16}$ showed female TMJs are more mobile than men at any age. Greater laxity of the joint has been observed in females than in males. The higher prevalence of women with some degree of TMD may be related to typical physiologic differences between females and males such as regular hormonal variations, muscular and bony structure, and different characteristics of the connective tissue.

\section{Conclusion}

The present study showed about $22 \%$ of the study population to have at least one symptom of TMD. The study showed that about $29 \%$ of the study population had at least one sign without the presence of any symptom. High prevalence of jaw deviation, clicking, and interferences in protrusion and lateral excursions was reported in participants that did not report any TMD pain. The data obtained from this study highlighted the need to carry out screening to send affected individuals for further treatment. This can help to prevent problems that predispose individuals to TMJ pain. Thus, extra emphasis should be given on the determination of the etiology of TMD along with the examination. Prevention and treatment at an early stage will prevent the progression of TMD.

\section{Clinical Significance}

The signs of TMDs may not always be accompanied by symptoms. Patients may remain asymptomatic for a long period of time before the symptoms are set in. The signs and symptoms of TMD are varied and may be overlooked when associated with other concurrent symptoms like earache, headache, neuralgia, and tooth pain. Since the treatment of the TMDs is different from these concurrent symptoms, it is necessary to diagnose and treat TMDs early and independently. Thus, it is important to create awareness among the dental fraternity and the dental students, so that treatment can be provided at an early stage.

\section{References}

1. Griffiths RH. Report of the President's conference on the examination, diagnosis, and management of temporomandibular disorders. J Am Dent Assoc 1983;106(1):75-77. DOI: 10.14219/jada.archive.1983.0020.

2. Nomura K, Vitti M, Oliveira AS, et al. Use of the Fonseca's questionnaire to assess the prevalence and severity of temporomandibular disorders in Brazilian dental undergraduates. Braz Dent J 2007;18(2):163-167. DOI: 10.1590/s0103-64402007000200015.
3. Schiffman E, Fricton JR. Epidemiology of TMJ and craniofacial pain: diagnosis and management. In: Kraus SL. The TMJ Disorders Management of the Craniomandibular Complex. New York: Churchill Livingstone; 1998. pp. 23-38.

4. Ohrbach R, Gonzalez Y, List T, et al., Diagnostic Criteria for Temporomandibular Disorders (DC/TMD) Clinical Examination Protocol: Version 02 June 2013. www.rdc-tmdinternational.org, Accessed on September 10, 2017.

5. Majumder K, Sharma S, Dayashankara Rao JK, et al. Prevalence and sex distribution of temporomandibular disorder and their association with anxiety and depression in Indian medical university students. International Journal of Clinical Medicine 2015;06(08):570-578. DOI: 10.4236/ijcm.2015.68076.

6. Manfredini D, Basso D, Salmaso L, et al. Temporomandibular jointclick sound and magnetic resonance-depicted disk position: Which relationship? J Dent. 2008;36(4):256-260. DOI: 10.1016/j. jdent.2008.01.002.

7. LeResche L. Epidemiology of temporomandibular disorders: implications for the investigation of etiologic factors. Crit Rev Oral Biol Med 1997;8(3):291-305. DOI: 10.1177/10454411970080030401.

8. Kim HI, Lee JY, Kim YK, et al. Clinical and psychological characteristics of TMD patients with trauma history. Oral Dis 2010;16(2):188-192. DOI: 10.1111/j.1601-0825.2009.01626.x.

9. Egermark I, Magnusson T, Carlsson GE. A 20-year follow-up of signs and symptoms of temporomandibular disorders and malocclusions in subjects with and without orthodontic treatment in childhood. Angle Orthod. 2003;73(2):109-115. DOI: 10.1043/0003-3219(2003)732.0.CO;2.

10. Wang MQ, Xue F, He JJ, et al. Missing posterior teeth and risk of temporomandibular disorders. J Dent Res 2009;88(10):942-945. DOI: 10.1177/0022034509344387.

11. Ebrahimi M, Dashti H, Mehrabkhani M, et al. Temporomandibular disorders and related factors in a group of iranian adolescents: a cross-sectional survey. Journal of Dental Research, Dental Clinics, Dental Prospects 2011;5(4):123-127. DOI: 10.5681/joddd.2011.028.

12. Hoffmann RG, Kotchen JM, Kotchen TA, et al. Temporomandibular disorders and associated clinical comorbidities. Clin J Pain 2011;27(3):268-274. DOI: 10.1097/AJP.0b013e31820215f5.

13. Manfredini $D$, Lobbezoo F. Relationship between bruxism and temporomandibular disorders: A systematic review of literature from 1998 to 2008. Oral Surg Oral Med Oral Pathol Oral Radiol Endod 2010;109(6):e26-e50. DOI: 10.1016/j.tripleo.2010.02.013.

14. Sonnesen $L$, Bakke M, Solow B. Malocclusion traits and symptoms and signs of temporomandibular disorders in children with severe malocclusion. Eur J Orthod 1998;20(5):543-559. DOI: 10.1093/ ejo/20.5.543.

15. Lakshmi S, Dyasanoor S. Association between psychological distress and occlusion among temporomandibular disorder patients - a clinical study. Int J Med and Dent Sci 2016;5(2):1198-1207. DOI: 10.19056/ijmdsjssmes/2016/v5i2/100608.

16. Beighton $\mathrm{PH}$, Solomon L, Soskolne CL. Articular mobility in an African population. Ann Rheum Dis 1973;32(5):413-418. DOI: 10.1136/ ard.32.5.413. 